\title{
SUPPORTING SOLVING WORD PROBLEMS INVOLVING RATIO THROUGH THE BAR MODEL
}

\author{
Siti Nurain Said ${ }^{1}$, Khairul Amilin Tengah*2 \\ ${ }^{1}$ Rimba II Secondary School, Ministry of Education, Brunei Darussalam \\ ${ }^{2}$ Universiti Brunei Darussalam, Brunei Darussalam
}

\begin{tabular}{l} 
Article Info \\
\hline Article history: \\
Received Sep 27, 2020 \\
Revised Jan 31, 2021 \\
Accepted Feb 1, 2021 \\
\hline
\end{tabular}

\section{Keywords:}

Bar Model,

Brunei Darussalam,

Mathematics Word Problem,

Problem Solving,

Ratio

\begin{abstract}
The weak ability for students to correctly attempt word problem question in mathematics have pushed researcher to study multiple approach in attempting such questions. This study examined the effectiveness of the Bar Model as a problem solving heuristic in improving Year 8 students' performance in solving word problems involving ratio. A total of thirty-three Year 8 students from a secondary school in Brunei Darussalam were involved in the study. Data were collected through pre-test and post-test. Paired sample t-test on the mean score of pre-test and post-test showed a significant improvement in the students' mean marks $(t=-8.079)$. The results also revealed that the Bar Model is capable of helping students of all abilities particularly the weaker students. Hence for this study, the Bar Model successfully enhanced the lower secondary students' performance in solving word problems involving ratio, particularThy when presented as public examination questions.
\end{abstract}

Copyright $(2021$ IKIP Siliwangi. All rights reserved.

\section{Corresponding Author:}

Khairul Amilin Tengah,

Sultan Hassanal Bolkiah Institute of Education,

Universiti Brunei Darussalam,

Tungku Link Road, Gadong, Bandar Seri Begawan, Brunei Darussalam.

Email: khairul.tengah@ubd.edu.bn

\section{How to Cite:}

Said, S. N., \& Tengah, K. A. (2021). Supporting solving word problems involving ratio through the bar model. Infinity, 10(1), 149-160.

\section{INTRODUCTION}

Students' poor academic achievement in mathematics has always been a concern and a worrying issue in Brunei every year. These poor results are reflected in all examinations at both national and school levels, and one such example is the national examination for Year 6 pupils, Penilaian Sekolah Rendah (PSR) before students enter the secondary level. In 2014, it was reported that only $62.29 \%$ of pupils managed to get grades $\mathrm{A}$ to $\mathrm{C}$ in mathematics for that year's PSR (Jalil, 2015), whereas in 2015, the percentage increased to only $64.81 \%$ (Hajar, 2015). Although there was an improvement, the percentage was still considered low when compared to the other four subjects that the pupils sat for. There are several possible explanations for this low mathematics performance and one of them is the inability of the pupils to solve mathematics word problems, which is an integral component of such public examinations, and mathematics content specifically (Saman, 2000; Raimah, 2001; Pungut \& Shahrill, 2014). 
Brunei changed its old education system to a new one in 2009 to keep up with the fast changing world. The new system has identified problem solving skills as one of the essential skills for the 21 st century in mathematics at both primary and secondary levels. Some of the aims and focus under the new mathematics curriculum are the ability to interpret and communicate mathematics processes, mathematics reasoning and visualisation. The new National Education System for the 21st Century, SPN21, suggests six modes of mathematics representations, namely, real life, verbal, concrete, symbolic representations, technology and diagram.

A mathematics word problem is defined as a written description of some situation (Greer, 1997). Whereas, Charles (2011) defined it as a real life situation in which both related known and unknown quantities given and described, a question is asked to determine value of unknown through one or a combination of operations to solve the problem. Students who can form mathematical algorithms may not necessarily be able to solve word problems if they do not have the ability to apply mathematical concepts that they already learned in different situations given.

According to Saman (2000), a large number of Year 6 pupils in the country find mathematics word problems to be difficult especially when multiplication and division are involved. While there are several factors that contribute to students' poor performance in solving word problems, some of the common problems that are observed are such that they do not know when to apply certain mathematical concepts, students tend to misinterpret mathematical concepts (Chin \& Clements, 2001; Vaiyatvutjamai \& Clements, 2004) and they lack the ability to visualise the mathematical problem and subsequently cannot form the appropriate arithmetical algorithm to solve the problem. Khalid and Tengah (2007) stated that most students are unable to understand what is being asked when attempting word problem tasks.

There are a considerable number of problem solving strategies developed by mathematicians to help students solve word problems. One effective strategy that can be taught to students is the famous Polya's four-step problem solving strategy: understand the problem, devise a plan, carry out the plan and look back at the solution (Polya, 2004). Liu and Soo (2014) suggested several ways that students can devise a plan to solve a problem, such as work backwards, guess and check, look for a pattern, choose an operation, act it out, make a list, simplify the problem, draw a picture. The common strategy used by teachers in Brunei is the use of keyword or phrases in attempting such word problem. Examples of keyword include 'altogether', 'more than' and 'total' for addition, and 'less' and 'reduced' for subtraction. These at times might cause errors as students that uses keywords or keyphrases approached tend to ignore the whole context of the question being asked and just focuses on the keyword. For example: I have three marbles more than Ali, and we have 9 marbles altogether. How many marbles do Ali have? For such example, several students will look at 'altoghter' or 'more than' as addition process and add 9+3 marbles, where in context the question should be focusing on subtraction.

In visual representation approach in mathematics, model(s) that reflect information is created to understand the problem as a whole (van Garderen \& Montague, 2003). The use of visual representation to model a mathematical problem has been known to be useful and powerful to aid students in the problem solving process (Pungut \& Shahrill, 2014; Denis, 1991; Piaget \& Inhelder, 1966), particularly in word problem. Creation, interpretation, utilisation and reflection on pictorial representation enable students to develop greater understanding of the topic when they are able to form strong link between representations and abstract concepts (Arcavi, 2003) and take into account the whole context of the problem. The ability to visualise mathematics concepts is what distinguishes competency between high and low achieving mathematics students (van Garderen, 2006). 
An example of a tool for visual representation is the application of Bar Model. The Bar Model uses a series of bars or rectangles to model a word problem, and take into account of the whole context of the problem and actual question being asked, where the bars represent the quantities in the problem and the relationship between given and unknown quantities is made clear through diagrams created by the students. The Bar Model method was developed in 1983 in Singapore by its Ministry of Education to address a national problem in the 1980s with the goal to raise mathematical competencies and improve problem solving abilities (Kho, Yeo \& Lim, 2009). Therefore, it would be worth to determine if applying Bar Model should be considered as an alternative approach by Brunei teachers when teaching their students.

There are two main types of the Bar Model and they are the part-whole model and the comparison model (Liu \& Soo, 2014). A variation of these two main types has resulted in other types of Bar Models. The use depends on the quantities and situation given in the word problem. The Bar Model can be used across many topics and some of them include whole numbers, fractions, ratio and percentage.

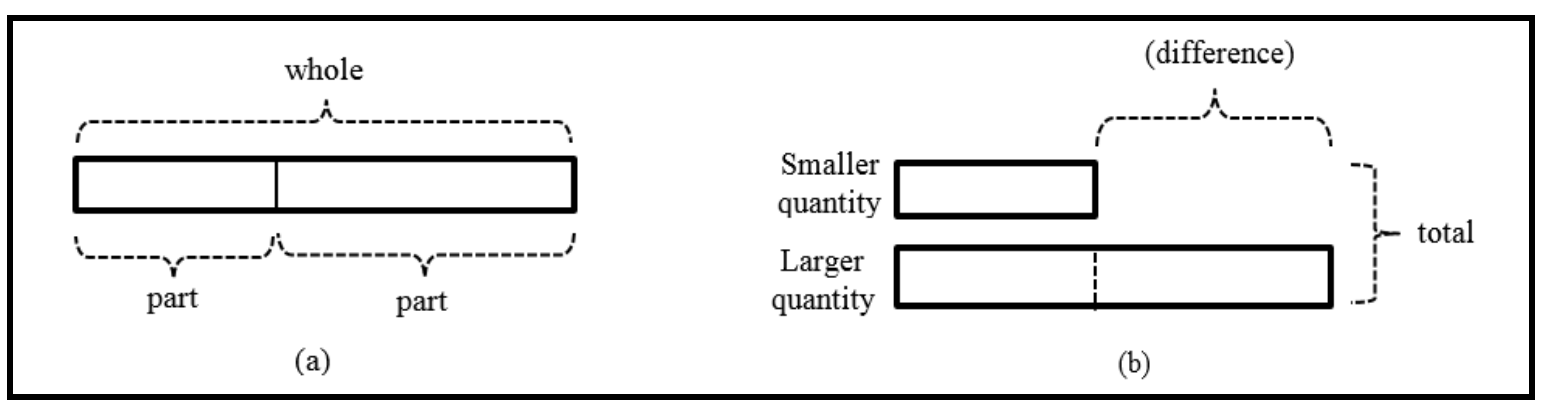

Figure 1. A part-whole (a) and a comparison (b) Bar Model, as illustrated by Madani et al. (2018)

As explained by Liu and Soo (2014), the comparison model can be used to relate or compare two quantities in the problem. The model shows the difference between the quantities and this helps to reduce students' reliance on equating the terms 'more than' to addition and 'fewer than' to subtraction because depending solely on key words may not be helpful after all as 'more than' does not necessarily mean to add. Figure 1 shows both partwhole and comparison Bar model.

For ratio problems, the comparison model is suitable to represent the quantities in the problem, hence the focus of this research intervention lessons. Ratio is about comparing two or more quantities. Word problems involving ratio require students to understand the relationship between the quantities contained in the problem and apply the correct arithmetic operations. However, students often fail to see the relationship and subsequently unable to form the correct arithmetical algorithm. With a Bar Model, the relationship between the quantities can be visually shown and this enables students to decide on the mathematical procedure to use (Liu \& Soo, 2014). Whilst bar diagram is useful in solving word problems, care must be taken when drawing the bars. Ng and Lee (2009) cautioned that every detail of the information in the text must be clearly, precisely and correctly translated to ensure correct solution of the word problem.

The purpose of this research study was to examine the impact of using the Bar Model method on the academic achievement of students in solving word problems involving ratio through the use of Bar Model. The research question used to guide this study was: How does the Bar Model affect students' performance in word problems involving ratio? 


\section{METHOD}

Convenient sampling of thirty-three participants from two Year 8 classes enrolled in an all-girls secondary school in the Brunei-Muara district were involved in this experimental research study. The participants have mixed mathematical abilities ranging from high to low. English language is their second language and their age ranged from 12 to 13, and all had already learned the topic ratio previously.

The pre-test and post-test in this study contained the same questions. The ten questions were in the form of simple word problems on ratio and were designed to include different levels of difficulty from easy to challenging (see Figure 2). The questions, adapted from past SPE papers and SPN21 mathematics Year 8 textbook, include asking students to form ratio of two quantities, finding missing quantities given the ratio, finding the total quantities as well as finding difference in quantities.

1. There are 10 boys and 14 girls in a field trip. What is the ratio of boys to girls?

2. The total number of fruits in a basket is 30 . There are 12 apples and the rest are oranges. What is the ratio of the number of apples to the number of oranges?

3. The ratio of green M\&M's to yellow is 2:5. If there are 20 yellow M\&M's, how many green M\&M's are there?

4. The ratio of the weight of Wani's cat to the weight of Azam's cat is 5:7. Wani's cat weighs $20 \mathrm{~kg}$. How much does Azam's cat weigh?

5. The ratio of the number of students who wear glasses to the number of students who do not wear glasses is 2:3. If there are 25 students in the class, how many students do not wear glasses?

6. The ratio of red to green crayons in a box is 3:5. If there are 9 red crayons, what is the total number of crayons in the box?

7. The ratio of the number of Dina's comics to the number of Alif's comics is 5:2. If Dina has 15 comics, how many comics do they have altogether?

8. Farhan and Azim get paid $\$ 49$ for washing cars in a day. They split the money in the ratio 4:3. How much more does Farhan receive?

9. The ratio of boys to girls at the football game is 5:3. There are 33 girls. How many more boys are there than girls?

10. A rope that is 18 metres long is cut into three strips in a ratio of 2:3:4. How long is the longest piece?

Figure 2. The 10 items in pre-test and post-tests

Prior to collecting data at the school of study, the validity and reliability of the test had been previously checked. A test-retest reliability method was administered to a group of twelve students not involved in the main study, produced correlation coefficient of 0.783 . This positive correlation between the test and the retest shows that the test questions are reliable in producing stable and consistent results.

Both descriptive (mean, median, standard deviation) and inferential statistics were used in the analysis of the collected data to answer the above research question, namely through students' overall scores and item-analysis of correct versus incorrect responses. For the pre-test and post-test, the sample paired t-test was used to analyse the results quantitatively to measure if there is a significant difference in students' achievement before and after introducing the Bar Model method. 
The intervention lessons were delivered over the course of three lessons within a week and each lesson took one hour. The introduction lesson focused on introducing concept underlying Bar Model in this topic. It included testing whether students know how to evaluate the unknown quantities of given two bars, and constructing and partitioning bars of required quantities (see Figure 3). Here, the unitary method was the students' preferred method to find the unknown quantities, where they calculated the value of 1 unit first by dividing appropriately and then once known, they multiplied it by the number of parts of the unknown quantities. Similar approach was used in the deconstruction of the bar, where information were extracted from drawn bars. Without the mention of the topic ratio, students received proper scaffolding when they transit from drawing bars to word problem. Once the students were confident, this skill was transferred to represent different ratios using bars, which was covered in the end of the first and throughout the second lesson.

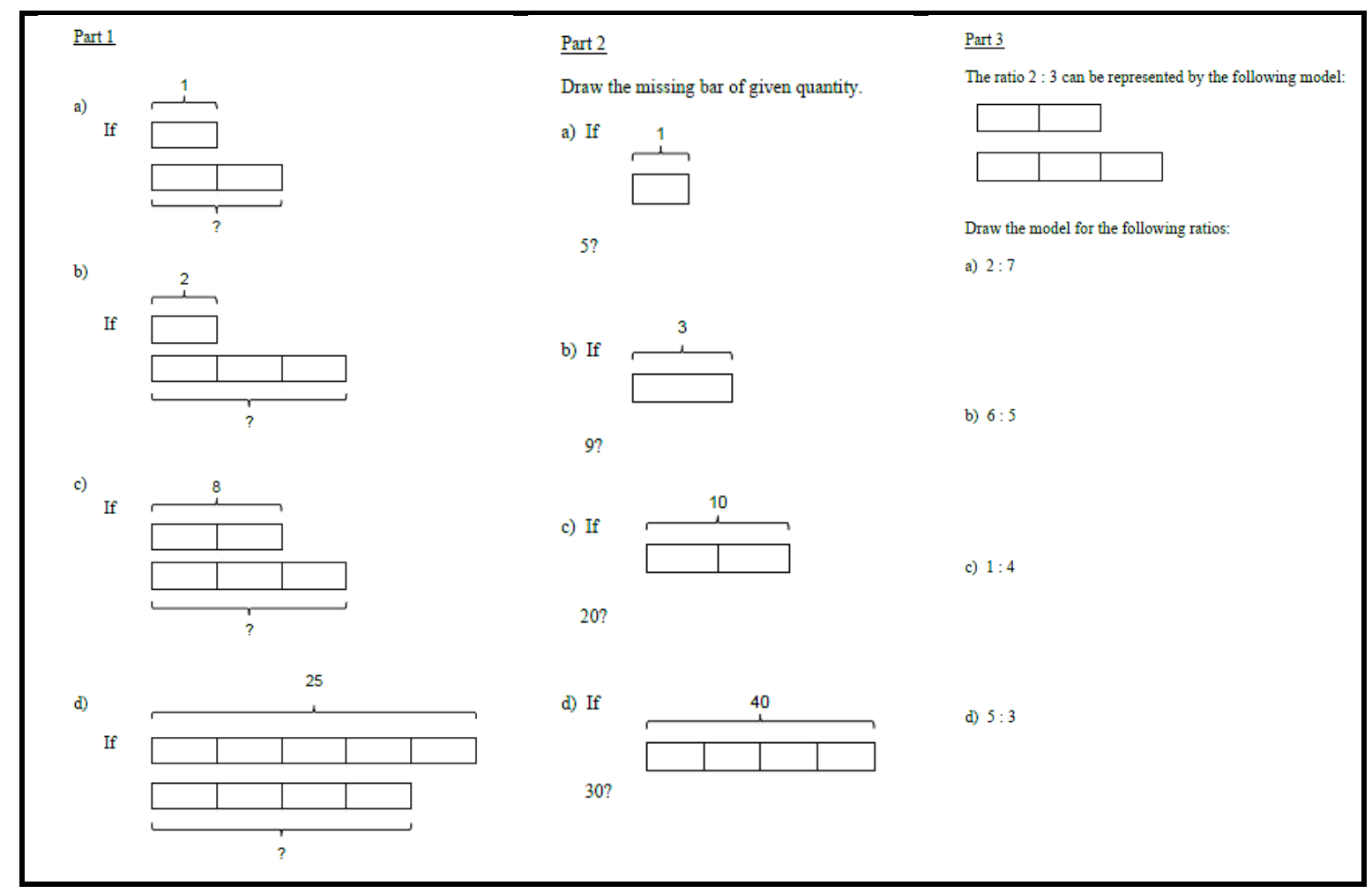

Figure 3. Questions in lesson 1, focusing on understanding the concept and drawing of Bar Model

In the second lesson, the students continue to represent ratio using bars as well as to solve word problems involving ratio using the Bar Model method. In this lesson, the importance of having accurate and correct size bars following the information in the word problem was emphasised. Students learned to label the model correctly to represent the known and unknown quantities and finally utilised the model appropriately to solve the problem. The practice problems were varied, ranging from simple to slightly more challenging problems (see Figure 4). 
1. Hayati made 20 white chocolate cookies and 16 milk chocolate cookies. What is the ratio of milk chocolate cookies to white chocolate cookies?

2. At a summer camp the ratio of boys to girls was 5:4. If there were 45 boys, how many girls were there?

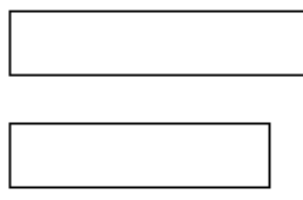

3. A classroom had 24 glue sticks. If the ratio of glue sticks to glue bottles was $4: 3$, how many glue bottles did the classroom have?

4. There were 220 girls who watched tennis. Some of these girls wore caps. The ratio of the number of girls wearing caps to the number of girls not wearing caps was 4:7. How many girls did not wear caps?

5. Bella gave a pocket money of $\$ 100$ to her daughters, Hani and Emma, in the ratio 2:3. How much did Emma receive?

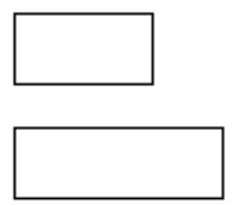

6. Kerrie ordered helmets and basketballs in the ratio 3:8. She ordered 64 basketballs. How many sports items did she order altogether?

7. The ratio of Karen's CDs to Mary's CDs is 5:6. If Mary has 66 CDs, how many CDs do they have altogether?

8. Azimah bought chicken and beef for a barbecue in the ratio 5:3. If she bought $6 \mathrm{~kg}$ of beef, how much chicken did she buy?
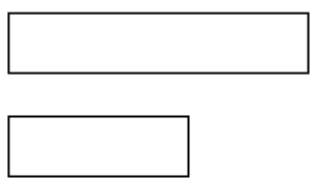

9. The ratio of the weight of Meg's cat to the weight of Anne's cat is 5:7. Meg's cat weighs $20 \mathrm{~kg}$. How much more does Anne's cat weigh?

10. Nina has a bag of 30 candies. The ratio of strawberry to orange to grape candies in the bag is $3: 2: 1$. How many orange candies are there?

Figure 4. Word problems in lesson 2 with and without prepared Bar Model

In the final lesson, students worked on the provided worksheet to practise solving word problems using the Bar Model (see Figure 5). They were encouraged to work in pairs and then by themselves to solve the given ratio problems. Selected students were invited to explain their solutions to the whole class and this was used for class discussions. It was during this lesson as well that any errors demonstrated by the students were identified and corrected on the spot so that students could learn from their mistakes. 
1. A box of candy has 14 pieces total. If two of the pieces are cherry flavoured, what is the ratio of other flavours to cherry flavored pieces?

2. The ratio of girls to boys in a chess club was 5:4. There were 32 boys. How many girls were there in the club?

3. In a bag of red and green candies, the ratio of red candies to green candies is $3: 4$. If the bag contains 120 green candies, how many red candies are there?

4. The ratio of girls to boys in a swimming club was 1:3. There were 11 girls. How many total members were there in the club?

5. A teacher had 18 red pens. If the ratio of red pens to blue pens she owned was 3:5, how many pens did she have total?

6. A necklace is made using gold and silver beads in the ratio 3:2. If there are 100 beads in the necklace, how many are gold and silver beads?

7. Jack and Nina share a reward of $\$ 140$ in a ratio of 2:5. How much of the total reward does Jack get?

8. At an ice cream shop the ratio of chocolate ice cream sold to vanilla ice cream sold is $3: 4$. If there are 12 chocolate ice cream sold, how many more vanilla ice cream would be sold?

9. In one day a movie store rented out 9 comedies. If the ratio of comedies rented to action movies rented was 1:5, how many more action movies were rented?

10. A truck is carrying pear juice, cherry juice, and apple juice bottles in a ratio of $3: 1: 3$. If there are 16 cherry juice bottles, then how many juice bottles in total are there?

Figure 5. Word problems used in lesson 3 at different complexity

\section{RESULTS AND DISCUSSION}

As seen in Figure 6, in the pre-test, only two students managed to achieve the maximum mark of 10 while there were eleven students scored zero. More than half of the students did not score past mark of 5, with only fifteen students obtaining marks 5 and above. These low scores indicated students' poor performance and ability in solving word problems involving ratio to begin with.

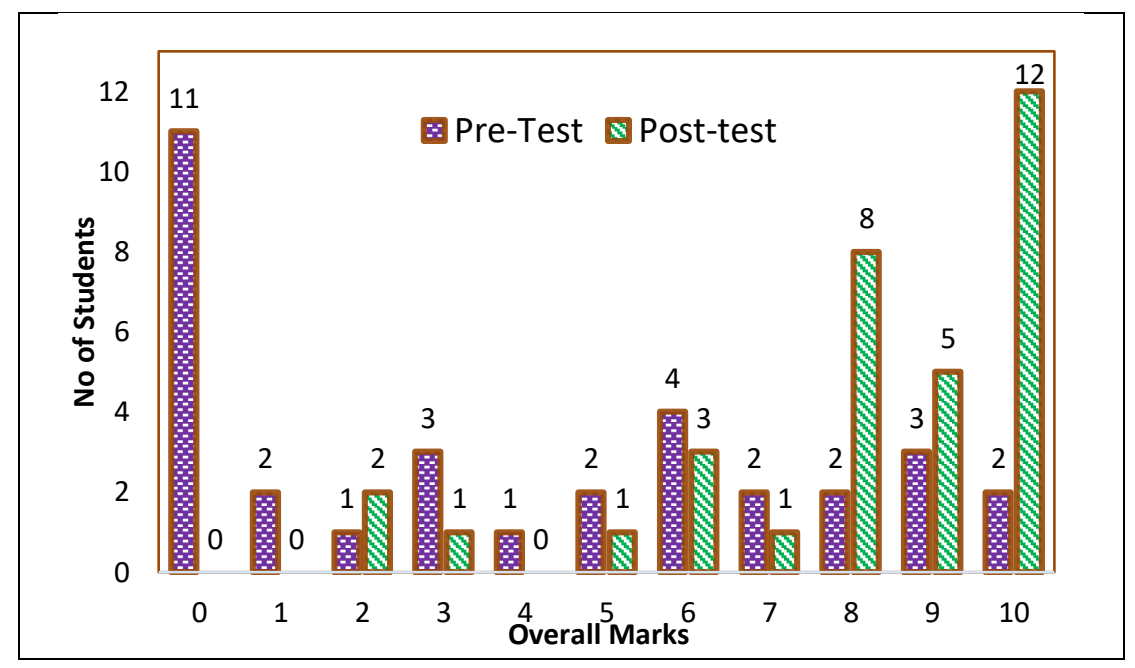

Figure 6. Bar chart of students' overall marks in the pre-test vs. post-test

In the post-test, overall improvement can be seen in the number of students obtaining higher marks, with considerable reduction in the lower end. Only two students obtained the lowest mark of 2 whereas twelve scored the maximum mark of 10. The bar chart also shows that a majority of the students successfully scored 5 marks and above, with just three getting 
mark 0-4. A total of twenty-five students obtained high marks of 8 and above, making up $76 \%$ of the sample.

Table 1. Descriptive statistics of pre-test and post-test of the two classes

\begin{tabular}{ccccccc}
\hline & Test & N & Minimum & Maximum & Mean & Std. Dev \\
\hline \multirow{2}{*}{ Class X } & Pre-test & 18 & 0 & 10 & 6.17 & 2.995 \\
& Post-test & 18 & 7 & 10 & 9.17 & 1.043 \\
\hline \multirow{2}{*}{ Class Y } & Pre-test & 15 & 0 & 6 & 1.13 & 1.995 \\
& Post-test & 15 & 2 & 10 & 6.73 & 2.738 \\
\hline \multirow{2}{*}{ Overall } & Pre-test & 33 & 0 & 10 & 3.88 & 3.603 \\
& Post-test & 33 & 2 & 10 & 8.06 & 2.318 \\
\hline
\end{tabular}

Table 1 summarises the performance of each class as well as the whole group's pretest and post-test. Students in the study school were grouped into classes according to their abilities or more specifically, their primary Year 6 PSR results. Class X was supposedly made up of students of high to average abilities, whereas, Class Y had students of low academic levels. The mean marks of the pre-test is reflective of the classes' ability. The mean mark of pre-test of class $\mathrm{X}$ was 6.17 , just slightly over the marginal mark of 5 . The marks in this class ranged from 0 to max 10. As expected, the low mean mark of class Y (M $=1.13$ ) reflected the low ability students' struggles in solving word problems involving ratio. The highest mark from this Class $\mathrm{Y}$ is just 6.

Both classes showed improvement in their class post-test result. The mean score increase in Class X to 9.17 implied great achievement overall. The small range of marks between 7 and 10 marks being the minimum and the maximum respectively indicated all the students in Class $\mathrm{X}$ scored in the high range. Likewise, Class $\mathrm{Y}$ also showed great improvement, with post-test mean mark of 6.73. A majority of the students obtained good mark with only three students who did not manage to score past 5 marks.

As a whole, the sample group produced mean mark of 3.88 for the pre-test, and increased to 8.06 in the post-test. Before the paired sample t-test for the students' marks was conducted, the four assumptions for the test were first inspected. Firstly, the dependent variable, which is the students' marks, was continuous as it measured from 0 to 10 . Due to the students' scores spread almost evenly within this range, there was no outliers. Thirdly, the same group of students was used for the pre-test and the post-test. Lastly, through visual inspection on the bar graph of the differences between the paired marks, the data was approximately normally distributed. With these conditions fulfilled, a paired-sample t-test was carried out to determine significance of the mean difference.

The paired sample t-test was used to test the following hypotheses:

$\mathrm{H}_{0}=$ There is no significant difference between the pre-test and post-test results.

$\mathrm{H}_{1}=$ There is a significant difference between the pre-test and post-test results.

Table 2. Paired sample t-test of pre-test and post-test for overall sample $(n=33)$

\begin{tabular}{|c|c|c|c|c|c|c|c|c|}
\hline & \multicolumn{5}{|c|}{ Paired Differences } & \multirow{3}{*}{$\mathbf{t}$} & \multirow{3}{*}{ df } & \multirow{3}{*}{$\begin{array}{c}\text { Sig } \\
(2- \\
\text { tailed })\end{array}$} \\
\hline & \multirow{2}{*}{ Mean } & \multirow{2}{*}{$\begin{array}{l}\text { Std. } \\
\text { Dev }\end{array}$} & \multirow{2}{*}{$\begin{array}{c}\text { Std. } \\
\text { Error } \\
\text { Mean }\end{array}$} & \multicolumn{2}{|c|}{$\begin{array}{l}95 \% \text { CI of } \\
\text { Difference }\end{array}$} & & & \\
\hline & & & & Lower & Upper & & & \\
\hline Pre- vs Post test & -4.182 & 2.973 & 0.518 & -5.236 & -3.128 & -8.079 & 32 & 0.000 \\
\hline
\end{tabular}

The t-test result revealed that there was a significant difference in the students' mean marks $(\mathrm{t}=-8.079)$ at $p<0.05$ level (see Table 2 ). Hence, the null hypothesis, H0, was 
rejected indicating that there is a significant difference between the pre-test and post-test results. This implied that the lesson intervention of the Bar Model method had successfully enhanced the students' performance in solving word problems involving ratio. This result is consistent with studies by Gani et al. (2019), Madani et al. (2018), Mahoney (2012), and Timah (2006), where the use of the Bar Model successfully improved the students' problem solving performance in their respective topics.

While the paired sample t-test of the overall sample has proven that the Bar Model method enhanced the sample students' performance in the problem solving involving ratio, the analysis of post-test results particularly shows that students with lower academic abilities in Class Y could have benefited greatly from the Bar Model strategy, given the bigger increase in mean from pre-test to post-test of Class Y from 1.13 to 6.73, compared to Class $\mathrm{X}$ with just mean increase of 3 . However, due to the limitation of small number of students in each class (15 in Class X and 18 in Class Y), t-test could not be used for significant difference test. From only 2 of them scoring 5 marks or more in the pre-test, this figure rose to 12 students in the post-test. A student from that class only obtained 1 mark in the pre-test but went on to obtain a full 10 marks in the post-test. The impact of the Bar Model method on the lower ability groups in solving word problems involving ratio is immense, as similarly found in Goh (2009), where the Bar Model method especially helped the weaker students in her study. Likewise, the Bar Model strategy helped all the mixed ability students in Class X to do well in the ratio test with a mean mark of almost 10. Furthermore, students performed significantly better in the post-test with thirty students scored 5 or more. This shows that the Bar Model is a problem solving heuristic that can cater to varying abilities of students but most significantly for the low abilities.

A comparison of the number of correct responses against the number of incorrect responses in the pre-test and post-test is shown in Figure 7. In the pre-test, there were clearly more incorrect responses than correct responses committed in almost all of the questions. Except for Q4 and Q5, more than half of the students could not solve the problems posed. Q2 and Q8 have the highest number of incorrect responses $(\mathrm{N}=27)$. Q4 has the lowest number of students giving incorrect responses $(\mathrm{N}=15)$, yet still considered high as almost half of the students failed to solve the problem.

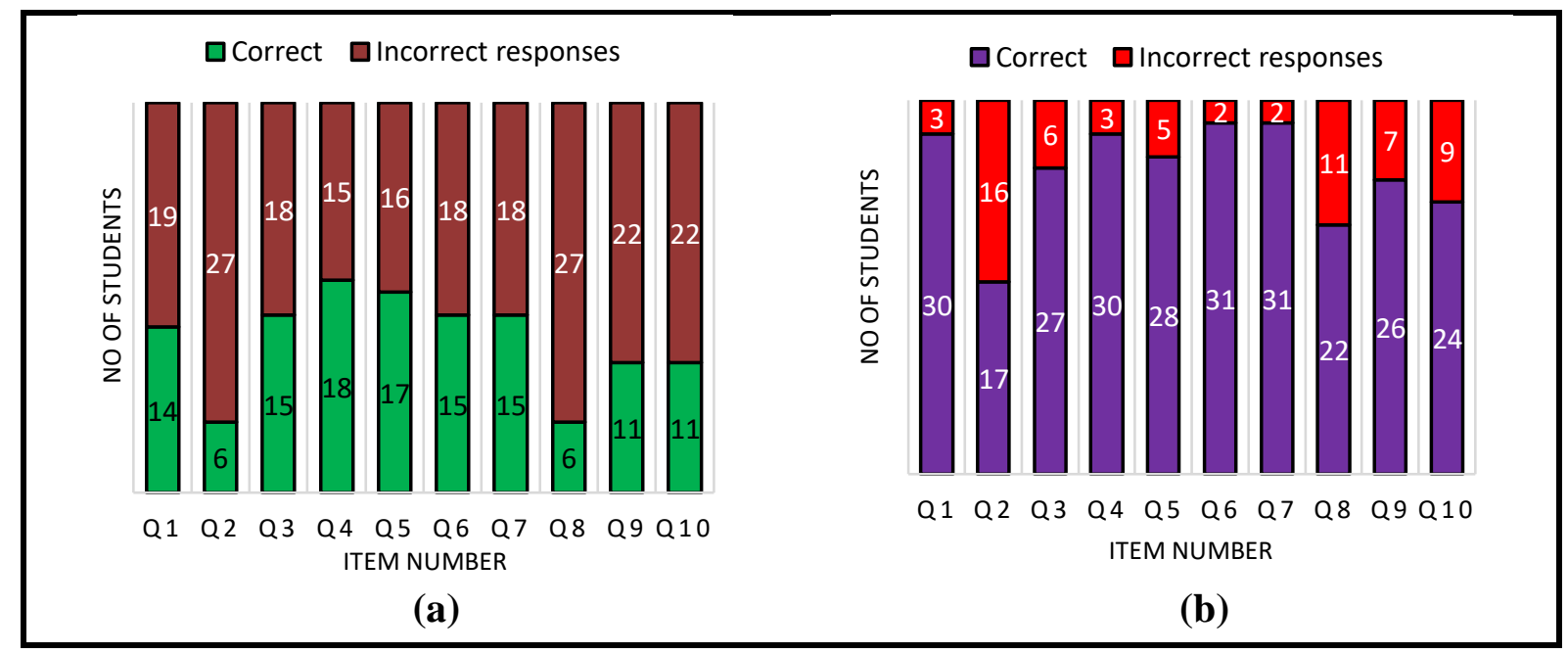

Figure 7. Comparison between the number of correct responses and incorrect responses in the pre-test (a) and post-test (b)

Looking at the post-test bars in Figure 7(b), there is clearly a great improvement in the number of correct responses in each question after the students learned the Bar Model 
method. More than half of the students could solve all the problems correctly in the post-test as opposed to in the pre-test. Questions 1,6,7 and 8 have the highest increase in correct responses by sixteen students. Meanwhile, questions 2 and 5 have the smallest increase (eleven students) in the number of correct responses but this is still regarded as high. Q2 which started with lowest correct responses in the pre-test ended up also being the lowest correct responses in post-test.

Overall, there is a positive indication of development in the students' problem-solving skills on ratio. The majority of the correct responses applied correct use of bar model in their answers in post-test, compared to keyword and unattempted questions in a pre-test. It suggests that teachers can consider different strategies for different topics such as: applying visual approach by using the graphic organizer in tackling word problem (Sian et al., 2016); implementing thinking aloud pair and Pólya in word problem approach (Simpol et al., 2017); strengthening pattern discovery skills in the problem-solving task (Tengah, 2011).

The use of the Bar Model is also one of the strategies adopted in Singapore classrooms taught as early as possible in elementary schools, thus making Singaporean students one of the best math problem solvers as reported in TIMMS and PISA. Besides, previous empirical studies have shown the Bar Model's effectiveness in improving students' performance in word problems in Singapore and Brunei (Gani et al., 2019; Madani et al., 2018; Mahoney, 2012; Timah, 2006). All of this is a good justification for introducing the Bar Model to students in the country to solve word problems.

This study particularly adds information to the existing body of knowledge regarding using the Bar Model in Brunei. The positive results are evidence that the Bar Model strategy can be implemented into the local classrooms. It is also hoped that this study can encourage and convince more teachers to start using this type of diagram representation as part of their instructional approach as recommended by the new curriculum (CDD, 2006a; 2006b). Furthermore, this Bar Model is very flexible and can be used across many topics such as whole numbers, fractions, and percentages. The Bar Model's simple nature, which does not consume time and money to teach, makes it a problem-solving heuristic that every mathematics teacher should practice as early as in primary levels across the country. Early exposure would help provide a strong solid foundation in mathematics for young children, according to one of the intended learning outcomes of the new mathematics curriculum (CDD, 2006a; 2006b). Moreover, the Bar Model's visual nature enables teachers to identify some of the difficulty's students have with word problems. That information would be useful for the teaching of word problems ( $\mathrm{Ng} \&$ Lee, 2005).

\section{CONCLUSION}

This study was to examine the effects of using the Bar Model method on secondary students' performance in solving word problems involving ratio. The results of the paired sample t-test revealed that there was a significant difference in the students' mean marks between the pre-test and post-test results. Furthermore, the results showed that students performed significantly better after they learned the Bar Model method as indicated by higher marks and more correct responses. Weaker students particularly benefited from the introduction of the Bar Model as evident in the number of students scoring 5 marks or more in the post-test. Hence for this study, the Bar Model successfully enhanced the lower secondary students' performance in solving word problems involving ratio. It is evident from this empirical study that the Bar Model method is capable of helping students of different learning abilities and it can be an effective alternative strategy to solving word problems involving ratio. 


\section{REFERENCES}

Arcavi, A. (2003). The role of visual representations in the learning of mathematics. Educational studies in mathematics, 52(3), 215-241. https://doi.org/10.1023/A:1024312321077

CDD. (2006a). Mathematics syllabus for lower primary school. Gadong: Curriculum Department, Ministry Of Education, Brunei Darussalam.

CDD. (2006b). Mathematics syllabus for upper primary school. Gadong: Curriculum Department, Ministry Of Education, Brunei Darussalam.

Charles, R. (2011). Solving word problems: Developing quantitative reasoning. Retrieved from

http://assets.pearsonschoolapps.com/playbook_assets/MatMon110890Charles_SW

P_Revise_eBook1.pdf

Chin, K. S., \& Clements, M. A. K. (2001). O-level students' understanding of lower secondary school geometry. In Energising science, mathematics, and technical education for all: Proceedings of the sixth annual conference of the Department of Science and Mathematics Education, 213-222.

Denis, M. (1991). Imagery and thinking. In Imagery and cognition, 103-131. New York: Springer. https://doi.org/10.1007/978-1-4684-6407-8_4

Gani, M. A., Tengah, K. A., \& Said, H. (2019). Bar Model as Intervention in Solving Word Problem Involving Percentage. International Journal on Emerging Mathematics Education, 3(1), 69-76. https://doi.org/10.12928/ijeme.v3i1.11093

Goh, S. P. (2009). Primary 5 pupils' difficulties in using the model method for solving complex relational word problems (Doctoral dissertation). Nanyang Technological University, Singapore.

Greer, B. (1997). Modelling reality in mathematics classrooms: The case of word problems. Learning and instruction, 7(4), 293-307. https://doi.org/10.1016/S09594752(97)00006-6

Hajar, S. (2015). Brunei sees improved results in PSR exams. Borneo Bulletin.

Jalil, I. (2015). PSR maths results still low: MOE. The Brunei Times.

Khalid, M., \& Tengah, M. K. A. (2007). Communication in mathematics: The role of language and its consequences for English as second language students. In Third APEC-Tsukuba International Conference Innovation of Classroom Teaching and Learning through Lesson Study III-Focusing on Mathematical Communication, CRICED, University of Tsukuba, 1-8.

Kho, T. H., Yeo, S. M., \& Lim, J. (2009). The Singapore model method for learning mathematics. Marshall Cavendish education.

Liu, Y. M., \& Soo, V. L. (2014). Mathematical Problem Solving - The Bar Model Method. Scholastic Education International. Singapore.

Madani, N. A., Tengah, K. A., \& Prahmana, R. C. I. (2018). Using bar model to solve word problems on profit, loss and discount. Journal of Physics: Conference Series, 1097(1), 012103. https://doi.org/10.1088/1742-6596/1097/1/012103 
Mahoney, K. (2012). Effects of Singapore's model method on elementary student problem solving performance: Single subject research (Doctoral dissertation). Northeastern University.

Ng, S. F., \& Lee, K. (2005). How primary five pupils use the model method to solve word problems. The Mathematics Educator, 9(1), 60-83.

Ng, S. F., \& Lee, K. (2009). The model method: Singapore children's tool for representing and solving algebraic word problems. Journal for Research in Mathematics Education, 40(3), 282-313.

Piaget, J. (1971). The psychology of intelligence. Boston: Routledge and Kegan.

Piaget, J., \& Inhelder, B. (1966). Mental imagery in the child. New York: Routledge \& Kegan Paul.

Polya, G. (2004). How to solve it: A new aspect of mathematical method (Vol. 85). New Jersey: Princeton university press.

Pungut, M. H. A., \& Shahrill, M. (2014). Students' english language abilities in solving mathematics word problems. Mathematics Education Trends and Research, 2014, 111.

Raimah, M. (2001). An investigation of errors made by primary 6 pupils on word problems involving fractions. Dissertation. Universiti Brunei Darussalam.

Saman, A. (2000). Investigating understanding by primary six pupils of word problems involving multiplication and division. Dissertation. Universiti Brunei Darussalam.

Sian, K. J., Shahrill, M., Yusof, N., Ling, G. C. L., \& Roslan, R. (2016). Graphic organizer in action: solving secondary mathematics word problems. Journal on Mathematics Education, 7(2), 83-90. https://doi.org/10.22342/jme.7.2.3546.83-90

Simpol, N. S. H., Shahrill, M., Li, H. C., \& Prahmana, R. C. I. (2017). Implementing thinking aloud pair and Pólya problem solving strategies in fractions. Journal of Physics: Conference Series, 943(1), 012013. https://doi.org/10.1088/17426596/943/1/012013

Tengah, K. A. (2011). Using simplified Sudoku to promote and improve pattern discovery skills among school children. Journal of Mathematics Education at Teachers College, 2(1). https://doi.org/10.7916/jmetc.v2i1.710

Timah, U. (2006). Primary 5 pupils' performance on mathematical word problems using model-drawing/box-diagram strategy. Dissertation. Universiti Brunei Darussalam.

Vaiyatvutjamai, P., \& Clements, M. A. (2004). Analysing errors made by middle-school students on six linear inequations tasks. Globalisation trends in Science, Mathematics and technical Education 2004, 173-182.

van Garderen, D. (2006). Spatial visualization, visual imagery, and mathematical problem solving of students with varying abilities. Journal of learning disabilities, 39(6), 496506. https://doi.org/10.1177/00222194060390060201

van Garderen, D., \& Montague, M. (2003). Visual-spatial representation, mathematical problem solving, and students of varying abilities. Learning Disabilities Research \& Practice, 18(4), 246-254. https://doi.org/10.1111/1540-5826.00079 